\title{
BIOGENIC SYNTHESIS OF ZINC OXIDE NANOPARTICLES USING LEAF EXTRACT OF JUSTICIA ADHATODA AND THEIR ANTIMICROBIAL ACTIVITY
}

\author{
Arun Kumar Khajuria*1, Fariha Chowdhary ${ }^{2}$ and Narendra Singh Bisht ${ }^{3}$ \\ ${ }^{1}$ Department of Botany, Cluster University Jammu, Jammu-180001, Jammu and Kashmir, India. \\ ${ }^{2}$ Department of Bio-Science, Arni University Kathgarh, Indora- 176401, Himachal Pradesh, India. \\ ${ }^{3}$ Department of Botany, H.N.B. Garhwal University Campus, Pauri Garhwal-246001, UK, India.
}

*Corresponding Author Email id: arun.khajuria20@gmail.com

Received: 20.11.2020; Revised: 4.12.2020; Accepted: 7.12.2020

CSociety for Himalayan Action Research and Development

\begin{abstract}
In the present study, an inexpensive green route has been demonstrated for the formation of $\mathrm{ZnO}$ nanoparticles by biogenic method using aqueous leaf extract of Justicia adhatoda which acts as a reducing and stabilizing agent. The synthesized $\mathrm{ZnO}$ nanoparticles were preliminarily characterized by UV-VIS followed by using different analytical techniques such as X-ray diffraction (XRD) and fourier transform infrared spectroscopy (FT-IR). The XRD pattern confirmed that, the synthesized $\mathrm{ZnO}$ nanoparticles are of hexagonal wurtzite structure with average calculated grain size less than $9.40 \mathrm{~nm}$. The FT-IR spectra indicated the presence of hydroxyl groups, carboxylic acids which may be responsible for biochemical reaction. The clear zone of inhibition against both gram- positive and gram-negative bacteria confirmed the antimicrobial potential of synthesized $\mathrm{ZnO}$ nanoparticles.
\end{abstract}

Key words: Biogenic, Zinc nitrate, Nanoparticles, XRD, FTIR, Antimicrobial activity.

\section{Introduction}

Nanotechnology, one of the modern techniques of material science is based on the manipulation of individual atom or molecule to produce new material at nanoscale level $(1-100 \mathrm{~nm})$ for function well below sub microscopic level (Jemal et al., 2017). New synthesized nano molecule exhibits completely new or improved properties based on size, distribution and morphology, with enhanced catalytic activity, thermal conductivity and non-linear optical performance (Sangeetha et al., 2011 and Sharma et al., 2018). Biosynthesized $\mathrm{ZnO}$ nanoparticles has drawn worldwide interest in past two-three years due to their facilitating properties i.e., biocompatible, biodegradable, less hazardous, non toxic, eco-friendly and wide range of applicability in different fields i.e., Agriculture, medical, electronic, optic and other material sciences (Sun et al., 2000; Schaffer et al., 2009; Balgobind et al., 2016 and Sharma et al., 2018).
Further, among all inorganic semiconductor nanoparticles, $\mathrm{ZnO}$ nanoparticles have attracted increasing attention because they are easy, inexpensive and safe to prepare. Besides, US FDA considered and enlisted $\mathrm{ZnO}$ nanoparticles as "Generally recognized as safe" (GRAS) metal oxide (Jayaseelan et al., 2012 and Agarwal et al., 2017).

Justicia adhatoda commonly known as Vasaka is a small evergreen, sub herbaceous bush of Acanthaceae family. The plant is distributed in the open sparse tree canopy habitat in tropical to subtropical areas upto 1450 masl (Khan et al., 2018). The plant is widely used in Ayurvedic, homeopathy and Unani systems of medicine (Bisht and Khajuria, 2014). The plant is equally popular in folk system of medicine and used to treat number of ailments (Sharma et al., 1992; Haider et al., 2011 and Khan et al., 2018). 
Pharmacologically plant is known to have antioxidant (Khan et al., 2018), antibacterial (Pa and Mathew, 2012; Bose and Chatterjee, 2015; Sharma and Kumar, 2016), antifungal (Fatima et al., 2016), antitussive (Barth et al., 2015), cardioprotective (Atal, 1980 and Chandhoke, 1982), anthelmintic activity (Sobia et al., 2018), hepatoprotective Activity (Afzal et al., 2013), haemagglutination (Khan et al., 2013) and anticancerous activity (Batool et al., 2017 and Latha et al., 2018).

Besides its medicinal value, plant is used as a hedge plant because the leaves of the plants are unpalatable to livestocks thus its cultivation as a hedge in areas where free-roaming, browsing livestocks can be a problem for field crops. Further, the value of the plant to be a bee forage plant is reported in different states (Sobia et al., 2018).

Thus in the present work, an attempt has been made to synthesize nanoparticles using leaf extract of Justicia adhatoda and evaluate their antimicrobial potential against gram positive and gram negative bacteria.

\section{Material and Methods}

Collection and processing of plant material: Leaves of Justicia adhatoda were collected from its natural population at village Kaptiyal, Tehsil Indora area of District Kangra, Himachal Pradesh, India. Collected leaves were washed thoroughly under tap water to remove all adhering soil particles. The washed leaves were then shade dried for more than 15-20 days. The dried leaf material was crushed into fine powder with the help of motor and pestle. Powdered leaves ( $8 \mathrm{gm}$ ) were soaked in $100 \mathrm{ml}$ distilled water in conical flask, followed by heating on the hotplate at constant temperature of $60^{\circ} \mathrm{C}$ for 10 minutes. The prepared extract was allowed to cool at room temperature and finally filtered with the help of filter paper. The final volume of the extract was made to $100 \mathrm{ml}$.

Green synthesis of Zinc Oxide nanoparticles: Zinc nitrate hexahydrate was used as precursor of
Zinc. The synthesis of $\mathrm{ZnO}$ nanoparticles was carried by mixing $100 \mathrm{ml}$ of the plant extract with $100 \mathrm{ml}$ of zinc nitrate hexahydrate extract in 500 $\mathrm{ml}$ flask. Prepared leaf extract was warmed for few minutes before the addition of Zinc extract in the flask slowly. After complete pouring, the mixture of both solutions was kept for vigorous stirring at constant temperature $\left(60^{\circ} \mathrm{C}\right)$ for 1 hour. The change in colour of the solution was considered as a visual marker for the synthesis of nanoparticles, followed by their precipitate formation. The precipitate formed in the reaction was allowed to settled down for overnight and collected by centrifuging the solution at high speed of $8000 \mathrm{rpm}$ for 10 mins. The collected pellets were washed with the help of double distilled water thrice followed by drying the pellets in oven for $10 \mathrm{hrs}$. at $60{ }^{\circ} \mathrm{C}$. Finally nanoparticles were homogenized using mortar and pestle and then collected in air tight bottles for further use.

\section{Characterization of synthesized nanoparticle:} Preliminary characterization of synthesized nanoparticles was made by visual markers. Secondary characterization of synthesized $\mathrm{ZnO}$ nanoparticles was carried out using different analytical tools i.e., UV-Vis, XRD (X-Ray Diffraction) and FTIR (Fourier Transform Infrared Spectroscopy).

Antibacterial assay: To study bactericidal effect of synthesized nanoparticles, four bacterial strains two gram positive (Staphylococcus aureus and Streptococcus pneumonia) and two gram negative (Klebsiella pneumoniae and Escherichia coli) were assayed by agar well diffusion method.

\section{Results and discussion}

During the synthesis of $\mathrm{ZnO}$ nanoparticles, change in the colour of reaction mixture from its initial stage (dark brown) to final stage (yellow brown) was used as positive indicator for the green synthesis of $\mathrm{ZnO}$ nanoparticles (Figure $1 \mathrm{a} \& \mathrm{~b}$ ). Further, confirmation of $\mathrm{ZnO}$ synthesis was carried out by using UV-VIS technique and 
obtained results showed peaks in the region at 340 to $390 \mathrm{~nm}$, which could be attributed to the $\mathrm{ZnO}$ nanoparticles.

The synthesized nanoparticles were then subjected to conformational details about the shape, size and functional group attached if any which may be responsible for reduction and capping of synthesized nanoparticles by the following methods.

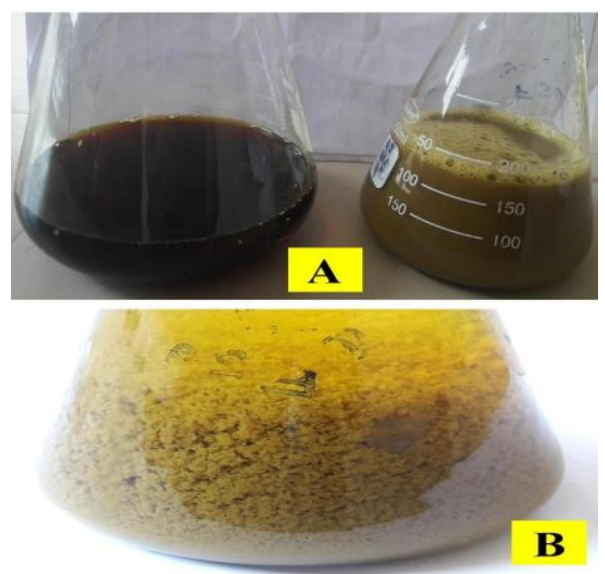

Figure 1: a \& b: $A=$ Change in colour indicating synthesis of nanoparticles. B=Image showing precipitate formation.

XRD analysis was carried out to study the crystallinity, size and shape of the unit cell of the synthesized nanoparticles using the diffraction of $\mathrm{X}$-ray. X-ray penetrates into the nano material and obtained diffraction patterns were compared with standards (ICSD) to get structural information. Each crystalline has its unique identity, thus used to determine, how the atoms packed together at what angle and what is the inter-atomic distance between them.

Size of nanoparticles were estimated by Scherrer's equation

$$
D=\frac{0.9 \lambda}{\beta \cos \theta}
$$

Where, $\mathrm{D}$ is crystallite size; $\boldsymbol{\lambda}$ is wavelength; $\theta$ is Bragg angle; $\boldsymbol{\beta}$ is Full width at half maxima Where, Bragg law is

$$
\begin{aligned}
& 2 \mathrm{~d} \sin \theta=\mathrm{n} \boldsymbol{\lambda} \\
& \mathrm{d}=\text { interplaner distance and } \mathrm{n}=\text { Order of } \\
& \text { diffraction. }
\end{aligned}
$$

The XRD spectra of leaf extract mediated $\mathrm{ZnO}$ nanoparticle showed crystalline nature of $\mathrm{ZnO}$ nanoparticles and the average calculated size using Debye-Scherrer's equation was less than $9.40 \mathrm{~nm}$. XRD spectra showed distinct peaks at $2 \theta=31.87,31.95,34.52,34.61,36.36,36.46$, $47.57, \quad 47.70, \quad 56.66, \quad 56.82, \quad 62.95,63.13$, confirming the hexagonal closed pack nano crystals (Figure 2).

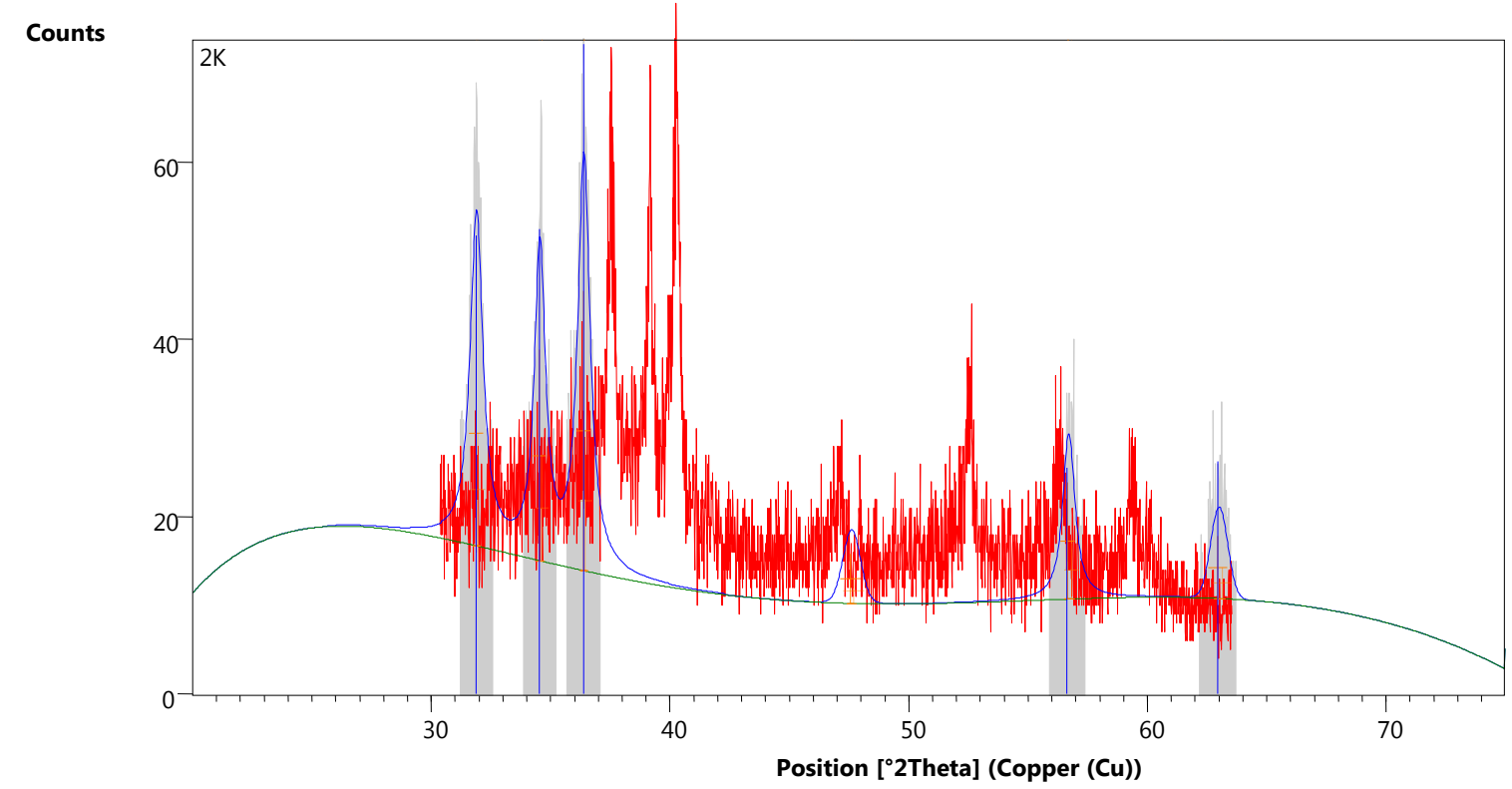

Figure 2: XRD Spectrum of $\mathrm{ZnO}$ nanoparticles synthesized using leaves of Justicia adhatoda 
FTIR spectra is used to analyse the presence of functional groups on the surface of synthesized nanoparticles. FTIR spectrogram of leaf based synthesized $\mathrm{ZnO}$ nanoparticles showed various peaks which corresponds to different organic groups. Broad band at $3400.18 \mathrm{~cm}^{-1}$ corresponds to the stretching vibrations - $\mathrm{OH}$ group (hydroxyl group). Further, peaks at $1595.70 \mathrm{~cm}^{-1}, 1513.40$ $\mathrm{cm}^{-1}, 1386 \mathrm{~cm}^{-1}$, and $1080 \mathrm{~cm}^{-1}$ which again corresponds to $\mathrm{C}=\mathrm{O}$ frequency of extensive conjugated system, $\mathrm{C}=\mathrm{C}$ aromatic stretchings, and C-O stretchings respectively (Figure 3 ). Further, presence of band at $538.40 \mathrm{~cm}^{-1}$ attributed to $\mathrm{ZnO}$ hexagonal structure.

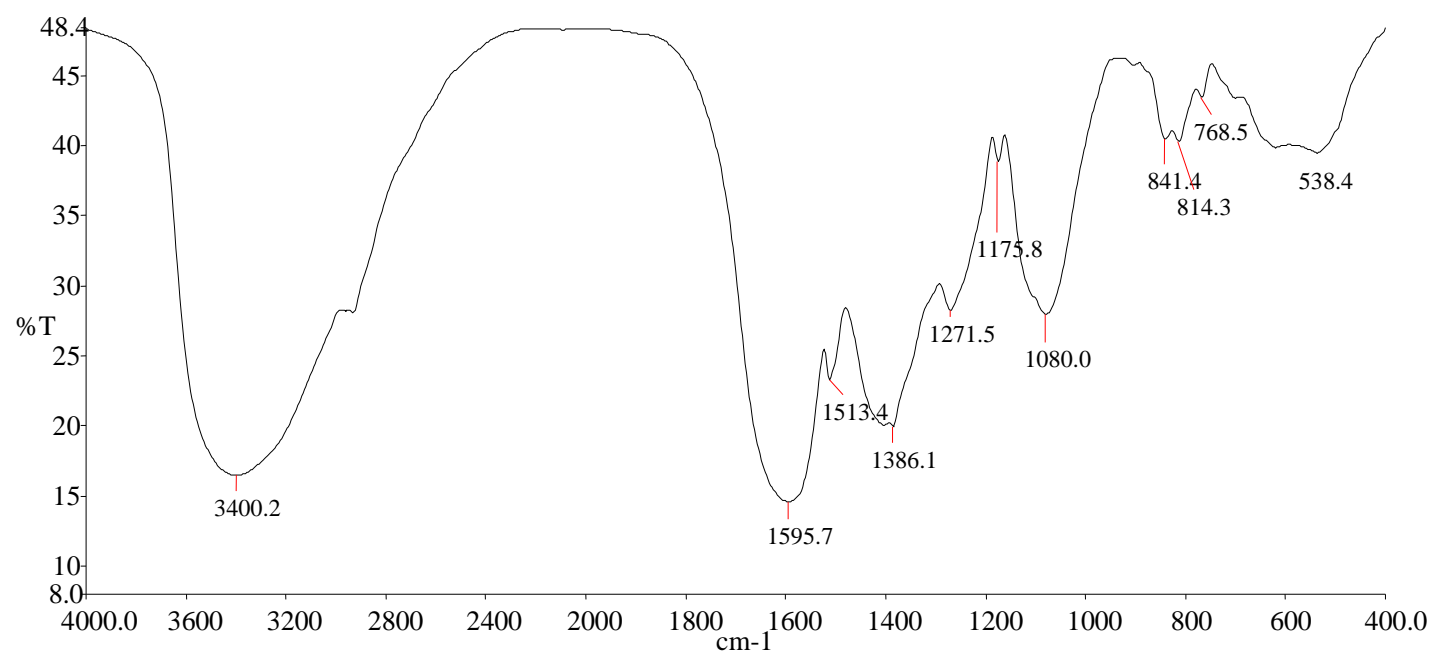

Figure 3: FTIR Spectrum of $\mathrm{ZnO}$ nanoparticles synthesized using leaves of Justicia adhatoda.

Synthesized $\mathrm{ZnO}$ nanoparticles $(100 \mu \mathrm{g})$ were used by well diffusion method against gram positive (Staphylococcus aureus and Streptococcus pneumoniae) and gram negative (Klebsiella pneumoniae and Escherichia coli) bacteria. Saline was used as control in the present study and it was found that saline have no effect on bacterial growth and gives no zone of inhibition. While $\mathrm{ZnO}$ nanoparticles showed antimicrobial potential against all test organisms. The maximum zone of inhibition $(12.90 \pm 0.36$ $\mathrm{mm})$ was reported for Staphylococcus aureus, while the minimum zone of inhibition $(9.77 \pm 0.40)$ was reported for E. coli (Table 1).

Table 1: Antimicrobial activity of leaf based $\mathrm{ZnO}$ nanoparticles against test organisms.

\begin{tabular}{|c|c|c|c|c|c|}
\hline $\begin{array}{c}\text { Concentratio } \\
\mathbf{n}\end{array}$ & \multicolumn{5}{|c|}{ Test organisms } \\
\cline { 2 - 6 } & Control & $\begin{array}{c}\text { Staphylococcu } \\
\text { s aureus }\end{array}$ & $\begin{array}{c}\text { Klebsiella } \\
\text { pneumoniae }\end{array}$ & E. coli & $\begin{array}{c}\text { Streptococcus } \\
\text { pneumoniae }\end{array}$ \\
\hline $100 \mu \mathrm{g}$ & 0.00 & $12.90 \pm 0.36$ & $12.60 \pm 0.79$ & $9.77 \pm 0.40$ & $12.47 \pm 0.83$ \\
\hline
\end{tabular}

\pm Standard deviation

The possible pathway may involve in this bactericidal activity production of reactive oxygen species, which cause dis-functioning of cell membrane of bacteria resulting in death of bacterial cell by oxidizing its membrane lipid layer (Akhtar et al., 2012; Setyawati et al., 2013 and Soenen et al., 2015). Findings of the present work are in correlation with the work of other workers i.e., Raghupathi et al., (2011), Senthkumar et al. (2014) and Naqvi et al., (2019) who reported that $\mathrm{ZnO}$ nanoparticles induce antibactericidal activity. 


\section{Conclusion}

The synthesis of crystalline $\mathrm{ZnO}$ nanoparticles with an average size of about $9.40 \mathrm{~nm}$ by green and environment friendly pathway using the plant extract of Justicia adhatoda as an effective reducing and capping chemical agent has been demonstrated. The role of phytochemical in reduction and capping was further confirmed by presence of phytochemicals on the surface of nanoparticles in FTIR studies. Nanoparticles showed good antimicrobial activity against tested micro-organisms. Thus, this route may contribute in the synthesis of stable $\mathrm{ZnO}$ nanoparticles to substitute to the physical and chemical methods and developing some reliable drug in the era of multi-drug resistance.

\section{Acknowledgment}

The authors are highly thankful to Dr. Vijyata Sharma (HOD Bio-Sciences), Arni University for providing lab facilities required during research work.

\section{References}

Afzal U, Gulfraz M, Hussain S, Malik F, Maqsood S, Shah I and Mahmood S (2013) Hepatoprotective effects of Justicia adhatoda L. against carbon tetrachloride (CCl4) induced liver injury in Swiss albino mice. Afr. J. Pharm. Pharmacol. 7(1): 8-14.

Agarwal H, Kumar SV and Kumar RS (2017) A review on green synthesis of Zinc oxide nanoparticles-An eco-friendly approach. Resour. Effic. Technol. https ://doi.org/10.1016/j.reffi t.2017.03.002.

Akhtar MJ, Ahamed M, Kumar S, Khan MM, Ahmad J and Alrokayan SA (2012) Zinc oxide nanoparticles selectively induce apoptosis in human cancer cells through reactive oxygen species. Int. J. nanomed. 7: 845-857.

Atal CK (1980). Chemistry and Pharmacology of vasicine: A new oxytocin and abortifacient. Indian Drugs. 15: 15-18

Balgobind K, Kanchi S, Sharma D, Bisetty K and Sabela MI (2016) Hybrid of $\mathrm{ZnO}$ NPs/MWCNTs for electrochemical detection of aspartame in food and beverage samples. J. Electroanal. Chem. 774:51-57.

Barth A, Hovhannisyan A, Jamalyan K and Narimanyan M (2015) Antitussive effect of a fixed combination of Justicia adhatoda, Echinacea purpurea and Eleutherococcus senticosus extracts in patients with acute upper respiratory tract infection: A comparative, randomized, double-blind, placebo-controlled study. Phytomedicine. 22(13): 1195-1200.

Batool R, Salahuddin H, Mahmood T and Ismail M (2017) Study of anticancer and antibacterial activities of Foeniculum vulgare, Justicia adhatoda and Urtica dioica as natural curatives. Cell. Mol. Biol. 63(9):109-114.

Bisht NS and Khajuria AK (2014) Ethnomedicinal plants of Tehsil, Kathua, Jammu \& Kashmir. J. Mountain Res. 9: 1-12.

Bose D and Chatterjee S (2015) Antibacterial activity of green synthesized silver nanoparticles using Vasaka (Justicia adhatoda L.) leaf extract. Indian J. Microbio. 55(2): 163-167.

Chandhoke N (1982). Vasicine, the alkaloid of Adhatoda vasica. Indian Drugs. 24: 425-426.

Fatima N, Mukhtar U, Ihsan-Ul-Haq MAQ, Jadoon M and Ahmed S (2016) Biological Evaluation of Endophytic Fungus Chaetomium sp. NF15 of Justicia adhatoda L.: A Potential Candidate for Drug Discovery. Jundishapur J. Microbio. 9(6).

Haider A, Junaid S, Hassan S and Abdul R (2011) Ethnobotanical profile of some plant resources in Malam Jabba valley of Swat, Pakistan. J. Med. Plants Res. 5 (18): 46764687.

Jayaseelan C, Rahuman AA, Kirthi AV, Marimuthu S, Santhoshkumar T, Bagavan A and Rao KB (2012) Novel microbial route to synthesize $\mathrm{ZnO}$ nanoparticles using Aeromonas hydrophila and their activity against pathogenic bacteria and fungi. Spectrochimica Acta Part A. 90: 78-84.

Jemal K, Sandeep BV and Pola S (2017) Synthesis, characterization, and evaluation of the antibacterial activity of Allophylus serratus leaf and leaf derived callus extracts mediated silver nanoparticles. J Nanomater. https ://doi.org/10.1155/2017/42132 75

Khan I, Ahmad H, Ali N, Ahmad B and Tanoli H (2013) Screening of Bunium bulbocastanum for antibacterial, antifungal, phytotoxic and 
haemagglutination activities. Pak. J. Pharm. Sci. 26(4): 787-791.

Khan I, Ahmad B, Azam S, Hassan F, Aziz A, Rehman N and Liaqat Z (2018) Pharmacological activities of Justicia adhatoda. Pak. J. Pharma. Sci. 31(2): 371377.

Latha D, Prabu P, Arulvasu C, Manikandan R, Sampurnam S and Narayanan V, (2018) Enhanced cytotoxic effect on human lung carcinoma cell line (A549) by gold nanoparticles synthesized from Justicia adhatoda leaf extract. Asi. Paci. J. Trop. Biomed. 8(11): 540-547.

Naqvi QU, Kanwal A, Qaseem S, Naeem M, Ali SR, Shaffique M and Maqbool M (2019) Size-dependent inhibition of bacterial growth by chemically engineered spherical $\mathrm{ZnO}$ nanoparticles. J. Biol. Phy. https ://doi.org/10.1007/s1086 7-019-9520-4

$\mathrm{Pa}$ R and Mathew L (2012) Antimicrobial activity of leaf extracts of Justicia adhatoda L. in comparison with vasicine. Asi. Paci. J. Trop. Biomed. 2(3): 1556-1560

Raghupathi KR, Koodali RT and Manna AC (2011) Size-Dependent Bacterial Growth Inhibition and Mechanism of Antibacterial Activity of Zinc Oxide Nanoparticles. Langmuir. 27:4020-4028.

Sangeetha G, Rajeshwari S and Venckatesh R (2011) Green synthesis of zinc oxide nanoparticles by Aloe barbadensis miller leaf extract: structure and optical properties. Mater. Res. Bull. 46:2560-2566.

Schaffer B, Hohenester U, Trugler A and Hofer F (2009) High-resolution surface plasmon imaging of gold nanoparticles by energy filtered transmission electron microscopy. Phys. Rev. B. 79:041401

Senthilkumar SR and Sivakumar T (2014) Green tea (Camellia sinensis) mediated synthesis of zinc oxide $(\mathrm{ZnO})$ nanoparticles and studies on their antimicrobial activities. Int. J. Pharm. Pharm. Sci. 6:461-465.

Setyawati MI, Tay CY, and Leong DT, (2013) Effect of zinc oxide nanomaterials-induced oxidative stress on the p53 pathway. Biomaterials. 34(38): 10133-10142

Sharma A and Kumar A (2016) Antimicrobial activity of Justicia adhatoda. World J. Pharm. Sci. 5:1332-1341.

Sharma D, Sabela MI, Kanchi S, Bisetty K, Skelton AA and Honarparvar B (2018) Green synthesis, characterization and electrochemical sensing of silymarin by $\mathrm{ZnO}$ nanoparticles: experimental and DFT studies. J. Electroanal. Chem. 808:160-172.

Sobia, Nawaz H, Khan S and Nadeem F (2018) Use of Malabar Nut (Justicia adhatoda L.) from Traditional Medicine to Current Pharmacopeia - A Review Study, IJCBS, 13:46-51

Soenen SJ, Parak WJ, Rejman J and Manshian B (2015) Intra cellular stability of inorganic nanoparticles: effects on cytotoxicity, particle functionality, and biomedical applications. Chem. Rev. 115(5): 2109-2135.

Sun S, Murray C, Weller D, Folks L and Moser A (2000) Monodisperse FePt nanoparticles and ferromagnetic FePt nanocrystal superlattices. Science.287:1989-1992. 